\title{
Classified Book and the Forming of China Culture and Literature Stereotypes
}

\author{
Han Ruihui
}

\begin{abstract}
Media plays a key role in the forming of culture and literature since the media transmits cultural and literary information for human being. Classified book, as an important reference book for numerous intellectuals, has attracted considerable attention scholarly for its unique edition form. However, previous studies of classified book have not dealt with the relationship among classified book, the forming of China culture and literature stereotypes, the power and knowledge. The aim of this research was to discuss the relationship among classified book, the forming of China culture and literature stereotypes, the power and knowledge. The research is based on the analysis of the origin of classified book, the national competition examination for official career and the booming of classified book in Song dynasty. Results showed that generally the abnormal inheritance of throne caused the edition of classified book, and the classified book's booming in Song dynasty led to the stereotypes of China culture and literature with the effect of national competition examination. The findings can contributed to a better understanding of the forming of stereotypes of China culture and literature. It implies that the imperial power influenced China culture and literature stereotypes indirectly and knowledge and power were indispensable to each other in feudal times of China until Late-Qing dynasty, when the western knowledge was introduced to China. Classified book is the typical example of that condition.
\end{abstract}

Keywords: classified book; stereotype; imperial power; national competition examination; knowledge

\section{INTRODUCTION}

The media is critical to the forming of culture. The different medias are related to the different cultures, for example, the art of printing was one reason for the Renaissance in Europe, in Song dynasty, the art of printing was also the cause for the cultural change. In modern and contemporary world, the invention of telegraph, mobilephone and internet has all been changing the human culture.

Literature is a factor that plays the long and deep role in culture. Much cultural meanings was derived from literary works, because literary works in history could be inherited easily and intactly. In other words, the cultural meanings have great relationship with such language arts.

The carrier of such language arts is critical to the circulation of language arts, because the readers relied on the carrier to obtain the message they wanted. In the different epochs of history, the main carrier were different, for example, in primitive times, Chinese ancestors recorded the events by the knots of rope. When the printing technique was invented, they used the presswork to circulate the ideas and messages.

The different carriers mean different cultures. The different carriers caused the different circulations, for example, the different speeds and scales of circulations. So the cultural phenomena will be different in the different carriers condition.

There was several times in China history that the cultural changes were ascribed to the changes of carriers. The typical one was the change in Song dynasty. The emphasis on literary works, the thrive of the urban, the national competition examination for official career and the improvement of civic education all contributed to the booming of the printing. The printing industry of Song laid the foundation of the model of ancient printing. In the changing process of carrier, the culture phenomenon of Song changed correspondingly. 
The classified book publishing of Song was one significant and critical factor in the forming of such change. Classified book was similar to the encyclopedia of the western world, which appeared in France of the Enlightenment Movement, or it could be said as Chinese encyclopedia in ancient times. The difference of classified book from the encyclopedia is that the classified book's objective is for the students' learning and literary creation superficially and that the Chinese classified book does not classify the categories and scientifically and precisely. Nevertheless, the classified book printing thrived in Song dynasty due to the numerous students want to pass the national competition examination for official career. The classified book was necessary for their study. So in such condition, the classified book was the bestseller.

The thriving of classified book caused the change of culture in Song dynasty and influenced the culture of following times profoundly. The intellectuals of Song dynasty preferred the national competition examination for official career, especially for the intellectuals of lower classes, such examination was almost the only one fair way to the better life. The authors of literary works in ancient China were the intellectuals, whether they passed the examination or not. So it could say that the intellectuals decided the basic model of Chinese literary works. The classified book of ancient China was critical for the learning and literary creation of the intellectuals, so the classified book played important role in the basic literary model in ancient China. The booming of the intellectuals in Song dynasty stimulated the publishing of classified books. Then the classified book influenced the intellectuals' learning and literary creation in return. The thriving of intellectuals in that times also influenced the literary creation thereafter.

\section{LITERATURE REVIEW}

During the past 30 years, much more information about Chinese classified book has became available. Searching CNKI (China National Knowledge Infrastructure) with the key word "classified book"(类 书), one will find 1,203 results. The research of classified book in China can be divided into different aspects: the research about the categories of classified book, (Liu Quanbo. 2011); the influences of classified book on Chinese vocabulary (Chen Donghui. 2014); the relationship between classified book and literature art. (Ci Bo. 2005)

This article will focus on the relationship among classified book and power and the forming of Chinese culture. It is now well established from a variety of studies, that the classified book has intimate relation with politics. (Wu Hao. 2001) Many historians have argued that the classified books were edited by intellectuals organized by the royal families. It has been noted that the ascending to the throne and the urgent politic unrest are all the stimulations for the editing of classified books. (e.g. Zhao Yuling. The Classified Book and China feudal Regime. Library and Information. 1987(4),109-114;Wu Hao. Officially Compiled Reference Books and Politics, Journal of Yangzhou College of Education. 2001(4),23-28) However, previous researches about Chinese classified book have failed to demonstrated any connection between classified book and the forming of China culture exactly.

It is interesting that the published books in Song dynasty boomed. The phenomenon could be ascribed to the emphasis of the emperors on the civil administration, the national competition examination for official career, and the improvement of the publishing techniques. (He Zhongli \& Zheng Jin.2003) There is also someone else ascribes the booming of publishing industry in Song dynasty to the accumulation of the literary works in Song dynasty. (Wang Liwei. 2010) As for the classified book, some researchers believe that the publishing of such kind of book is one measure of the emperors to administrate the intellectuals. (Ci Bo. 2004) Overall, these studies highlighted the need for the analysis on the publishing of classified books in Song dynasty. The research on the publishing of classified book in Song dynasty can provide for us with some aspiration about the function of it in China culture forming.

\section{The Origin And Development of AnCIEnt Classified Book In China}

Most of the researchers believe that Huang Lan is the first classified book in China. It was edited by the intellectuals organized by the emperor of Wei Dynasty Cao Pi. The main objective of the book is to collect the previous books. The collected books in Huang Lan are classified into different groups, 
which count to 8 million Chinese characters. Actually, such editing had appeared in the period of Cao Cao. Unfortunately, the book failed to be handed down to the next generation in Tang Dynasty.

There are different types of classified books. It can be divided into the general classified book and the specialized classified according to the different contents. The former contains all kinds of matters and the later contained only the specialized matters. According to the different editors, the classified book can be divided into three types: the books edited by the country, the books edited by private and the books edited by the publishing house. The classified books edited by the country involved the editors organized by the government. With the huge finance and human resources, such kinds of classified books' content would be extensive and with the regular pattern. The classified books edited by the private were mainly for the purpose of literary creation. The classified books edited by the publishing house were prompted by the development of publishing techniques and the thirst for money.

After Wei Dynasty, the classified books became more. There were many classified books edited by the nobilities and officials. In Sui and Tang dynasties, the classified books became more and the scale of such books became more extensive. Compared to the previous classified books, the pattern of them became more perfect and standard. In Song and Ming dynasties, the classified books edition became the climax in China history. Especially in Song dynasty, the four classified books: Tai Ping Yu Lan, Ce Fu Yuan Gui, Tai Ping Guang Ji and Wen Yuan Ying Hua all contained the extensive categories. In Ming dynasty, Yong Le Da Diane, which is the hugest classified books in China, was edited by the government. In the earlier period of Qing dynasty, the society was stable and the economy was active and prosperous, with the accumulation of literature in previous dynasties, many classified books were edited with good quality.

The decline of classified books happened in Jiaqing period of Qing dynasty. After this stage, the classified books had the sudden shortage and disappeared in the last. Many factors contribute to the forming of such condition. On the one hand, the empire faced many crises, so it had no intention and strength to edit the classified books. On the other hand, the national competition examination for official career was abolished. As the necessary book for national competition examination, the classified books was almost of no use in that time in that its main purpose was for the national competition examination. Besides, the classified books were replaced by the encyclopedia introduced from the western world because the classified books' index was not as scientific as the encyclopedia of the western world. (Zhang Yunjin. 2004)

\section{The Edition OF Classified BoOKS BY THE Governments In ANCIENT ChINA}

One interesting phenomenon is the edition of classified books by the government in ancient times. One would find that those classified books were appeared after the unrest of society and politics.

The edition of Yong Le Da Dian is a good illustration of such phenomenon. Yong Le Da Dian is an extensive classified book in ancient China. Encyclopaedia Britannica claims Yong Le Da Dian is the hugest encyclopedia in the world. It contains the material of literary art, philosophical encyclopedia, history and geography before $14^{\text {th }}$ century of China. The volumes of it is 22,937 and the category book of it are 11,095 volume. All the Chinese characters it contains amount to three hundred and seventy million.

Nevertheless, the motivation to edit this classified book is necessary to be analyzed. In order to analyze the motivation, the background of the edition is imperative to be described. Zhu Di conquered Nan Jing in 1402 and seized the throne of his nephew. However, the ascending to the throne was illegal because 1) he ascended to the throne by military force, so that was regarded as usurping the throne; 2) Zhu Di, as an uncle, seized the throne from his nephew. That was deemed as trespassing the morality in China to some extent. Zhu Di ordered that one classified book should be edited one year after he ascended to the throne.

The editing process experienced two times. The first editor-in-chief was Xie Jin, an intellectual who had great learning. Under his supervision, classified book Yong Le Da Diane was accomplished in the next year. However, Zhu Di was not satisfied because the speed of edition was too fast. So he employed another editor, Yao Guangxiao, companying with Xie Jin to supervise the edition of Yong Le Da Dian. With the accompany of Yao Guangxiao, the edition speed became slow and after 5 years, the edition was finished in 1407. 
In the editing process, enormous money and time of the intellectuals was consumed. In order to get the books in the folk to edit the classified book, Zhu Di spent great money. So Zhu Di gave the image of an emperor emphasizing the education and literary arts, which was contrary to the tyrant who ascended to the throne by the military force.

The question is why Zhu Di was not satisfied with the fast speed of the edition. One would response to the question that Zhu Di wanted the editors to accomplish the book with better quality in slow speed. But the first editor-in-chief was Xie Jin, who was famous intellectual for his erudition. Xie Jin had the ability to edit the book with good quality in short period. So obviously, Zhu Di's discontent was not because of the quality of this classified book.

Zhu Di's discontent is because his motivations to edit the classified book was not meat. His motivations to edit this book was to establish the positive image and control the intellectuals. The first motivation was meat in that Zhu Di got his good reputation in the editing process. The second motivation to control the intellectuals was also meat in that when the speed was slow, more time and elaboration of the intellectuals would be spent in the edition of this book.

The role of the intellectuals is considerable question. They decided the public opinion and the historical image about the emperors. The intellectuals in ancient had the good education, especially the education for the national competition examination for official career. Preparation for the examination required them read numerous of books, especially the Confucian classics. The more important requirement was that they should have the ability to write articles and poems of excellent quality. Those articles and poems would be spread extensively because of the excellent literary techniques. That would form the stereotypes of the characters in the articles and poems and the public opinion in the process. A classic example of the process is Shakespeare's Macbeth. The real Macbeth in history was different from the Macbeth described in Shakespeare's tragedy, however, the Macbeth get well known in the world is the Macbeth in Shakespeare's tragedy, even the real Macbeth in history is forgot for many people.

To control the intellectuals was critical to Zhu Di. Controlling the intellectuals means controlling his historical image and public opinion of him. In order to control the intellectuals, Zhu Di ordered to edit the classified book, which needed the great money, time, human resource and elaboration. When the intellectuals engaged in the editing, they would not have much time to think about the image of the emperor. On the other hand, they got the salary from the emperor in the editing process, so their maintenance relied on the emperor. In the condition, they would not dare to issue the adverse opinion on the emperor.

So Zhu Di was not satisfied with the fast speed of editing. When the speed was slowed down, the more time, elaboration and human resource should be put into the edition. So the control would be easy for Zhu Di.

The eagerness of Zhu Di to control the intellectuals happened in the background that he ascended the throne with the abnormal measure and infringed the morality. The more unsafe he felt, the more eager he wanted to control the intellectuals. So Zhu Di order to edit the classified book one year after he ascended the throne and wanted the editing process should be slow and long.

Another example of the edition of classified book is Qun Shu Zhi Yao and Wen Si Zhai Yao. This classified book was edited by the intellectuals organized by Emperor Tang Taizong, Li Shimin. Li Shimin ascended to the throne in 626 A.D. by violence violent coup, in which he killed his brother and forced his father gave up his throne. Two years after he ascended to the throne, Li Shimin ordered some ministers and renewed scholars edited the classified book, Qun Shu Zhi Yao. In 641 A.D., the classified book Wen Si Bo Yao was accomplished with the order of Li Shimin. The political objective of the two books are apparent in that they wanted to establish the positive political image of Li Shimin and weaken the impression of Li Shimin's cruelty in the pursuit of throne, just as the main editor of Qun Shu Zhi Yao, Wei Zheng, said that the content of Qun Shu Zhi Yao as : "the redemption of the country by the emperor who sacrificed his own benefit, and the lost of the country by the emperor who were stupid, and the failure of the emperor who were too arrogant because of the victory..." (Wei Zheng. 1987) The main editor of Wen Si Bo Yao Said that the purpose of his classified book was to collect the rules of the emperors and the teaching of the sages and men of virtues. (Gao Shilian. 
1987 ) Since those famous classified books were edited in the order of Li Shimin, Li Shimin's political image became positive with the publishing of them.

The similar case is the classified book San Jiao Zhu Ying mainly edited by Zhang Zongchang, the toy-boy of Empress Wu Zetian in Tang dynasty. Just as the emperors had many wives, Empress Wu Zetian had many toy-boys, which incurred the rebukes in the folk and the minister groups. In order to calm down the rebukes, Empress Wu Zetian ordered her toy-boys Zhang Zongchang etc. to edit the classified book San Jiao Zhu Ying with the purpose to cover up her sandals and maintain the political stability and her status.

Another classic example is the edition of Huang Lan, which was edited in the order of Cao Pi, who ascended the throne with the abnormal measure. After he seized the throne, he organized some famous intellectuals to edit the classified book Huang Lan. It is critical to notice that the political situation after $\mathrm{Cao} \mathrm{Pi}$ ascended the throne was unstable. Some other political and military organizations regarded his throne as unjustified and illegal, besides, some ministers around Cao Pi had the grudge against him. In order to reinforce his status, he suppressed the hostile forces bloodily, on the other hand, he organized some renewed intellectuals to edit the huge classified book Huang Lan with the purpose to establish the positive image and ensure the legal and justice status.

\section{The Classified Books in Song Dynasty}

As discussed above, the edition of classified books has intimate relationship with the political intention of the emperors or empress in ancient China. One climax of classified book edition may be in Song dynasty. In one hundred years after the establishment of North Song dynasty, the edition of classified books had been continuous. As the reasons mentioned above, the edition of classified books in Song dynasty was mainly about the politics. The first emperor of Song dynasty realized that the military officials involved too much in the violent conflicts and did harm to the stability of his throne. So he paid attention to the civilian officials and weakened the status of the military officials. Accordingly, the emperors invested much in the literary studies. In the tenure of the third emperor of North Song dynasty, Emperor Song Zhenzong, he began to study the literary works just as he required others to do. That is embodied in the edition of classified books. Many intellectuals were involved in the edition and got their living in the edition, so the intellectuals would relied on the emperor, no matter they came from the ex-hostile countries or not. When the classified book edition was finished, the intellectuals involved in the edition would get much reward. The edition of classified books embodied the inclination of the emperors, and what is more important is that the edition controlled the intellectuals politically promoted the culture and literature.

The political intention of classified book edition is significant in the tenure of the second emperor of North Song dynasty, Emperor Song Taizong. The ascending to the throne of Emperor Song Taizong had met with great skepticism. First, when the first emperor of North Song dynasty died, there was no other courtiers beside. The courtiers only saw the first emperor put the axe erectly on the ground as if he did something violently. They heard that the first emperor shouted to Jin King beside him, who later became the second emperor, that he should be careful. So Emperor Song Taizong's seizure of the throne was mysterious. The skepticism of his death has more important reason that the first emperor of Song dynasty had two sons who had already got mature. According to the rules of the inheritance of throne in China, the first son of the emperor had the priority to inherit the status. However, the inheritance of the throne in this case was different: the younger brother ascended the throne after the former emperor passed away. One year after the ascending of the throne, the former emperor's two son's died mysteriously without the recording of cause of death in any formal official documents.

There were many other details that aggregated the mystery about the former emperor's death. After the former emperor died, the queen ordered the courtier summon her sons, but her sons were not summon up, instead, the former emperor's brother came and terrified the queen. Besides, after he ascended the throne, he kept watch on his another brother rigidly and that resulted in the sorrowful death of his brother at last. All the details demonstrated the skepticism of Emperor Song Taizong's obtaining of throne.

So reinforcing the status of was the prime matter to Emperor Song Taizong. Although the threat around the country was serious and much territory had already be invaded, Emperor Song Taizong 
was not eager to solve the problems mentioned above. Instead, he ordered to edit three huge classified books within four months after he ascended the throne. In the process, numerous intellectuals engaged in the editing, so they had little time and intention to question the legality of his throne. Besides, the intellectuals were controlled and their loyalty to the emperor was reinforced.

It is interesting to notice the phenomenon that the classified books boomed in Song dynasty, because the political turbulence of Song dynasty was similar to other dynasties in China history, however, the classified books were more than any pervious dynasties. The emperors of Song dynasties generally paid more attention to literature and were diligent in studying literary knowledge, and the further reformation of national competition examination for official career resulted in more examinees with the need of more classified books as the reference books, besides, the printing techniques of Song dynasty was improved significantly settled the foundation of the more publishing classified books, so the classified books in Song dynasty boomed. (He Zhongli \& Zheng Jin. 2003) Some other researchers believed that the culmination of literary works was one factor of the booming of classified books in Song dynasty. (Wang Liwei. 2010)

In all the factors, the improvement of printing technique and the thriving of publishing industry in Song dynasty were the basic condition for the booming of classified books. One would find that other books, such as political books, were also published more than the previous dynasties. The printing technique belongs to the media of literary circulation. With the reforming of media, the new cultural phenomenon would occur.

\section{The Change of Literary Art in Song Dynasty}

The classified book exerts great influence on China culture. It is one important factor that formed the stereotypes of China literary art and culture and the literary taste of China readers. In feudal China, the national competition examination for official career was critical to the life of the intellectuals. In the examination, many intellectuals changed their fates through getting the official status. The achievement in the examination was the same goal of almost all the intellectuals in feudal China. Numerous intellectuals exerted almost all their lifetime for the preparing of this examination. The classified book was one kind of the compulsory reference book for their examination, so the classified book influenced their learning. Even the intellectuals did not pass the examination, their literature creation would be influenced greatly by such kind of book. In order to discuss the process, the article will introduce the national competition examination for official career first.

The national competition examination for official career emerged in Sui and Tang dynasties. Before the period, the officials in China government were mainly appointed by the official of high ranks or elected in the folk. So in the process, the high rank officials and nobilities would monopolized the appointment of the officials. That would damage the system of the governmental administration. This examination broke the monopoly and made it possible that the common intellectuals could get the official careers and change their fortunes. The examination form lasted for 1,300 years and became the mode of talents selection which existed for the longest time in the world.

The examination was mainly about the recitation of the classic literature. In Sui and Tang dynasties, the examination was mainly about examining the recitation of the classic literature, the interpretation of the classic literature, and the creation of literary works. In Song dynasty, the content of the examination was almost the same with the content in Sui and Tang dynasties. Compared to the previous dynasties, Song dynasty pay more attention to intellectuals than the warriors. The examinations could be divided into three kinds: the examination for the intellectuals, the examination for the special talents and the examination for the warriors. The examination for the intellectuals was the most important. The examination for the intellectuals was held every three years. The examination became more important in Song dynasty because of the more emphasis of Song emperors on it. Although some famous high rank officials such as Wang Anshi, who was the prime minister for a period in Song dynasty, proposed the reforming of the examination, because he found the examination content could not select the real talents for the empire, the examination content kept the same with that of the previous dynasties.

In the preparing for this examination, the classic books played the important role and influenced the intellectuals greatly. From the examination content, it can find that the recitation of the ancient classic literary works and the literary creation were important for the official career. The classified book 
provided the examinees with the literary material for literary creation. So such kind of books was necessary to the examination. Some intellectuals and famous poets would create the literary works with the reference of classified books. Although some poets did not have the real experience and feelings, they would create the literary works which contained the experience and feelings according to such kind of reference books.

The categories of classified books in Song dynasty changed in Song dynasty. Before Tang dynasty, the content of the classified books was mainly about the narratives of events. After Sui and Tang dynasties, the content of classified books recorded both the events and the relevant literary classics, because the classified books became the necessary reference books for the intellectuals especially the intellectuals who prepared for their national examination. With the more violent competition, the more reference books appeared for the examinees. Among them, the classified book was one of the most effective reference books. So from the period, the classified became the necessary reference books for national examination but not only the book of recording ancient events and classic works.

The content of the classified books influenced the literary creation in the process. From the discussion in above section, it can find that the classified books boomed in Song dynasty because of the political reasons. Both the intellectuals passed the examination and the intellectuals who did not pass the examination would created literary works with the reference of classified books. The poem was necessary to the daily life of ancient China. "In the period from Six Dynasties to Qing dynasty, poem became more and more necessary in social intercourse. No matter in happy events, funeral arrangement, or daily communication, the poem played important role." "Even one renewed poet would not have so much real feeling and fresh thought for such poem creation." (Qian Zhongshu. 2002) So the classified books became necessary for their literary creation. So the classified books were the necessary books for China intellectuals no matter in the sphere of examination or the daily life. The renowned poet Yuan Mei said in his Yuan Mei on Poetry:"the classified books and the compilation of characters contain all. Even if $\mathrm{Zuosi}^{1}$ lived in the contemporary world, he would not create fu. Even if he created the literary work, he only need check the classified books and complete the work in one or two days. "Wang Yingzhi. 1993)

The booming of classified books in Song dynasty and the emphasis of the emperors on the national competition examination and literary art all promoted the forming China literary stereotypes in Song dynasty. The examinees and the intellectuals need create the literary works according to classified books, but according to their real feelings and experiences. So this process can be called as the reproduction of literary works, because the literary works were not produced with the real feelings and experiences but the previous literary works. So the previous literary image, plot, and background would be repeated in the new literary works. Then the literary stereotypes were formed in the process.

Literary art in Song dynasty was different from the literary art in previous dynasties, because the literary stereotypes were formed in Song dynasty and influenced the subsequent literary creation. In the process, the readers' literary taste was also stereotyped. The change of literary stereotype permeated into culture, and as a result, the cultural stereotypes of China was formed slowly in the course.

\section{IMPERIAL POWER AND THE FORMING OF CHINA LITERATURE}

The imperial power has profound exertion on China culture and literature. The exertion played its role in through its control on culture and literature. Classified book is one of the measure of the control.

The control of literature and culture was formed firstly in the sphere of communication media of literature and culture. Just as the article discussed in the previous section, the classified book influences the stereotypes of China literature and culture. The different media caused the different cultural modes, for example, the printing technique resulted in the Renaissance in Europe and the telephone, Mobilephone and Internet all have the different relationships with the culture-forming respectively. In Song dynasty, the printing technique had been improved significantly, so the publishing industry prospered with the merchants' pursuit for profit. Classified book was popular in

\footnotetext{
1 Zuo Si was the famous poet in Western Jin dynasty, who was specialized in fu, a descriptive prose interspersed with verse. His works such as $Q i D u F u$ is well-known for its elaborated rhetoric.
} 
that times because of the need of preparing for national competition examination. On the other hand, the emperors wanted the classified books could be published more because of their political needs. In the sense, the classified book publishing was encouraged by the imperial power. The classified book formed the literature and culture of China gradually in that it was the necessary reference of the ancient intellectuals.

Education is another measure of the imperial power to control literature and culture. The origin of national competition examination for official is the empirical power's need to reinforce itself. In Han dynasty, the administration talents were chosen by the local officials, however, this form of choosing could cause the expansion of the local power. So in Wei and Jin dynasties, the officials from the central government of the empire went to the different locals chose the talents with the magistrates, nevertheless, the corruption would happen from time to time in that the high rank officials acted in collusion with the magistrates. In Sui and Tang dynasties, the election of the talents was administrated by the central government to prevent the corruption from the collusion between the central governmental officials and the magistrates and avoid too many the descendents of the nobilities accessed into the official circle through the abnormal ways. In Ming and Qing dynasties, the emperors would invigilate the national competition examination, the examinees who passed the examinations were regarded as the students of the emperors. In China, the relationship between the teachers and students is one of the most intimate relationships. After the passed examinees got the high position in the official circle, they would have more intimate relationship with the emperors. So through this measure, emperors reinforced the relationship with the officials and his power and status. "The national competition examination was one kind of election institution in ancient China. It was situated in the feudal autocratic society, so it could not avoid its distinctive class nature. Its rigorous examination system was in the service for the ruling class. " (Gao Ang \& Sun Yan. 2005)

The national competition examination ensured the stability of the political function in ancient China. Through this examination, the social elites could be distributed in the different hierarchical power organizations according to their talents, knowledge and capacity. They also could mobilize in the different power organizations, so the power was balanced. "The traditional society relied on the opening of the high classes and the recognition of the low classes to the hierarchy. The elites of the high classes could be content for their power, wealth and prestige, and the would-be elites in low classes would not lose the hope because the high classes were opening. " (He Huaihong. 1998)

So the national competition examination is critical to both the empirical power and the intellectuals in folk.

In the process, the classified book exerted its powerful influence. The emperors organized the edition of classified books due to political reasons and the intellectuals needed such books for national competition examination and literary creation. The content of the classified books would also confirm the need of the emperors but not the reverse.

It can conclude that the imperial power shaped China literature stereotypes and culture indirectly. Although the imperial power had no intention to shape all China literature stereotypes and culture, the classified book accelerated the stereotyping of China literature and culture. Of course, some content of the classified book was determined by the need of the imperial power, for example, the loyalty to the emperors.

\section{The Relationship between KnOWledge and Power in China History}

British philosopher Bacon's celebrated dictum "knowledge is power" is suitable to described the situation in China history. However, it also can be said that "power is knowledge" in ancient China history.

The article will discuss on the power's effect on knowledge firstly. That power is knowledge is achieved basically by the imperial control of the intellectuals. This is evident in the case of literary inquisition in Qing dynasty. It is also certainly true in the case of the edition of classified book in the period of Emperor Kangxi in Qing dynasty. From 1673 to 1681, the Revolt of the Three Feudatories was suppressed by Qing government, however, the emperor was not satisfied with the victory and did not believe that the success could reinforce the status of the imperial power. So the emperors learned hard about China traditional culture, and on the other hand, the emperor summoned up many 
intellectual elites to edit the classified book from 1694. Pei Wen Yun Fu, Piano Zi Lei Bian, Zi Shi Jing Hua and Fen Lei Zi Jin were all edited under the organizing of Emperor Kangxi. The emperors of Qing dynasty also organized the intellectuals to edit The History of Ming Dynasty. The time of this edition lasted for 60 years. Many intellectual elites spent almost all their lifetime on this edition, however, the content of The History of Ming Dynasty was full of the distortion of actual history of Ming dynasty because of Qing dynasty emperors' intention to maintain and reinforce their ruling status. Qing dynasty is the dynasty which paid the most attention to the knowledge control in China history.

The literary content and ideology were also be controlled by the imperial power in China. The stimulation of the emperors to organize the intellectuals to edit classified books is to maintain and reinforce the stability of his ruling status. As for the content of classified books, it was determined by the emperors' will. Through editing the classified books, the emperors provided the intellectuals with the standard reading material. The thought control to the intellectuals was easily feasible in the process.

Secondly, the imperial power is reinforced by knowledge, or in other words, "Knowledge is power" as Bacon said. The ruling of the imperial power should be rationalized by the intellectuals, and that is especially true in the case that the emperors seized their status abnormally and unjustly. Such emperors would were inclined easily to organize the intellectuals to edit the classified books as this article has analyzed above.

Knowledge could achieve the social status and political privilege in feudal China. "Even if a gentleman ${ }^{2}$ has no land, he might have great power. However, he landlord without the status of gentleman could not have the right." (Zhang Zhongli. 1991)This condition is different from that in Europe. In Europe, the wealth, land and property were the factors resulted in the social transformation. However, in China, the social transformation in China was led by the knowledge change. This is evident in late Qing dynasty, the translation of the western knowledge was the herald of the social transformation. The collapse of Qing dynasty has relationship with the introduction of the western knowledge. "Before the destruction of Qing dynasty by guns and cannons in the Revolution of 1911, the spirit and soul of Qing dynasty had already be disorganized by the new knowledge system and ideology. " (Guo Jianqing. 2005)

China politics and knowledge combine with each other intimately. Guo Jianming said that "the stability of China traditional society is achieved by the intimate cooperation between the intellectuals with the ruling class, and the Confucian morality knowledge's flexibility. When the traditional knowledge could not resolve the political problems, the knowledge would be transformed. Then the previous foundation of the cooperation between the ruling class and the intellectuals would be weakened, because there was an either-or situation: the intellectuals and the ruling class accept the new knowledge and reform completely, or the new intellectuals depart with the ruling class and the traditional politics. The two conditions would both results in the transformation of the traditional politics. In other words, the whole new political crisis's smashing the traditional knowledge is the start point of knowledge transformation, and whether the transformation of knowledge succeed or not is the key to the success of political transformation." (Guo Jianqing. 2005 )However, what Guo Jianming said is true in late-Qing dynasty, when the western knowledge and the new consciousness were introduced to China. In the previous history of China, it would be found that the political power controlled the culture and knowledge firmly. China knowledge especially the knowledge for national competition examination for official career is different from that of the western world in the same period. China knowledge emphasizes on the inheritance of the previous knowledge but not the doubt for the previous knowledge. The intellectuals should recite numerous literary articles in preparing for the examination. The classified books were the suitable for the need. The edition for the classified books required the intellectuals collect, classify, compile and edit the numerous previous literary classics. They got their salary from the edition work, which consumed almost all their lifetime and vigor, so they had no intention to resist the government and had to cooperate with the government.

\footnotetext{
${ }^{2}$ In feudal China, an intellectual could get the status of a gentleman through passing national competition examination for official career, even if he did not join into official circle.
} 
(Xia Nanqiang. 2001) When the examinees read the classified books to prepare their examinations, they would also abide by the requirement of the books and previous moralities. It could find in the discussion above that the knowledge and the ruling political modes kept the significant stability in the condition until the western knowledge as the complete new knowledge was introduced to China. The classified book is the very typical example for the combination between the politics and the knowledge in ancient China.

\section{Conclusion}

The aim of the present research was to discuss the relationship between the classified book, the imperial and the forming of stereotypes of China culture and literature. This research has shown that the classified book shaped many stereotypes of China literature and culture. It is originated from the need of the emperors to maintain their ruling and political stability. However, when the national competition examination for official career prospered, the classified book became the necessary reference book for the examinees and boomed afterwards. That was phenomenal in Song dynasty. Song dynasty witnessed the turbulent political unstabilities caused by the abnormal inheritance of the throne and the subsequent many classified book editions. With the advanced printing techniques and prosperous publishing trades, the classified books boomed. Then the culture and literature of China stereotyped generally in Song dynasty with the factors such as violent competition examination, the booming of classified books and the previous literary accumulation.

This research has also shown that the imperial power controlled and shaped China cultural and literary stereotypes indirectly. Although the imperial power wanted to maintain their political status and stability in the first, the classified books they edited influence the examinees and the intellectuals in afterwards. With the accumulation of the literary creation according to the reference of the classified books, the cultural and literary stereotypes grew gradually.

Political and knowledge combined with each other intimately, and the classified book is the very typical example of that. The political power and the knowledge relied on each other in ancient China. In this process, the classified book both reinforced the imperial power and controlled the intellectuals. So it would find that the classified book is the result of the combination of power and knowledge.

The findings of this research suggests that power, knowledge, culture and literature of China were interacted with each other in ancient China, and the culture, literature and even the knowledge were stereotyped. The teaching of ancient China emphasized the inheritance of the previous knowledge intactly and did not encourage the innovation for the knowledge generally. This situation was aggravated by the national competition. So the culture, literature and even knowledge where inhered without change. That situation was continued until Late-Qing dynasty, when the western knowledge was introduced into China, which broke the combination of the traditional knowledge and power. In Late-Qing dynasty, the edition classified book ceased and was replaced by the encyclopedia. The national competition examination and imperial power also vanished in that time.

This research has provided a deeper insight into the forming of China culture and literature through the analysis of the origin and function of classified book in China history. It also enhance our understanding of the relationship among knowledge, power, culture and media before Late-Qing dynasty in China.

A limitation of this research is that it has not discuss the classified book phenomenon in the reference of knowledge, power, culture and media after Late-Qing dynasty due to the material factors. It would be interesting to analysis the classified book phenomenon of the period after Qing dynasty.

\section{REFERENCES}

Chen Donghui. Lei Shu and the Study of the History of Chinese Vocabulary. Research in Ancient Chinese Language. 2014(01), 80-85

Ci Bo. Poetry of Song Dynasty and Encyclopedia. Journal of Fuling Teachers College. 2005(6), 78-84

Ci Bo. Song Culture and the Prosperity of Classified Books. Jianghuai Tribune. 2004 (1), 130-135

Gao Ang \& Sun Yan. The Imperial Examination System and Ancient Chinese Politics. Journal of Qiqihar University. 2005(02). 19-21 
Gao Shilian. Preface to Essentials of Literature Thoughts Vol 134. Beijing: Zhonghua Book Company. 1987

Guo Jianqing. From the Traditional Knowledge Transformation to Traditional Politics Transformation: the Function of Translation of Books in Late-Qing Dynasty. Journal of Humanities. 2005(02). $42-48$

He Huaihong. The Election Society and Its Ending. Beijing: Sanlian Bookstore. 1998. 143

He Zhongli \& Zheng Jin. An Analysis of Leishu Boom in the Song Dynasty. Journal of Zhejiang University. 2003 (1) 31-38

Liu Quanbo. Encyclopedia's Evolution in Bibliography. Library and Information Service. 2011(23). $122-130$

Qian Zhongshu. The Selection of Song Poetry. Beijing: Sanlian Bookstore. 2002. 66

Wang Liwei. Classified Book in Dynasty's Status Among China Classified Books. Lexicographical Studies. 2010 (5), 142-151

Wang Liwei. Classified Book in Dynasty's Status Among China Classified Books. Lexicographical Studies. 2010（5), 142-151

Wang Yingzhi. The Complete Works of Yuan Mei. Vol 3. Nanjing: Jiangsu Ancient Book Publishing House. 1993. 319

Wei Zheng. The Preface to Essentials of Books Vol 141. Beijing: Zhonghua Book Company. 1987

Wu Hao. Officially Compiled Reference Books and Politics, Journal of Yangzhou College of Education. 2001(4),23-28

Xia Nanqiang. The Study on Classified Book. Wuhan: Hubei People's Publishing House. 2001. 168

Zhang Yunjin. The History of Chinese Category Books. Journal of Qiqihar University. 2004(1). 14-16

Zhang Zhongli. Preface to China Gentlemen: Their Function in China of $19^{\text {th }}$ Century. Shanghai: Shanghai Social Science Publishing House. 1991

Zhao Yuling. The Classified Book and China feudal Regime. Library and Information. 1987(4),109-114

\section{AUTHOR's BIOGRAPHY}

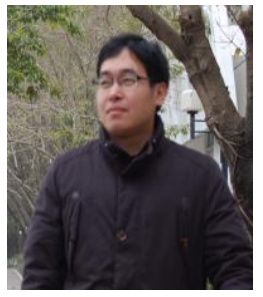

Han Ruihui, works in Jinan University. He received his $\mathrm{PhD}$ in Sun Yat-sen University in 2008. He is interested in interdisciplinary studies. 